\title{
Erratum to "A Cross-Joint Vivaldi Antenna Pair for Dual-Pol and Broadband Testing Capabilities"
}

\author{
Gwang-Hun Jeon · Philip Ayiku Dzagbletey · Jae-Young Chung*
}

\begin{abstract}
In the paper entitled "A Cross-Joint Vivaldi Antenna Pair for Dual-Pol and Broadband Testing Capabilities (Journal of Electromagnetic Engineering and Science, vol. 21, no. 3, pp. 201-209, 2021)”, the Acknowledgments has incorrect information. The correct statement should read.
\end{abstract}

This work was supported in part by the Institute of Information and Communications Technology Planning and Evaluation (IITP) funded by the Korea Government (MSIT) (No. 2017-0-00659) and in part by the Basic Science Research Program through the National Research Foundation of Korea (NRF) funded by the Ministry of Education (No. 2018R1D1A1B07049984).

Department of Electrical \& Information Engineering, Seoul National University of Science \& Technology, Seoul, Korea. "Corresponding Author: Jae-Young Chung (e-mail: jychung@seoultech.ac.kr)

This is an Open-Access article distributed under the terms of the Creative Commons Attribution Non-Commercial License (http://creativecommons.org/licenses/by-nc/4.0) which permits unrestricted non-commercial use, distribution, and reproduction in any medium, provided the original work is properly cited.

(c) Copyright The Korean Institute of Electromagnetic Engineering and Science. 